\title{
PO2-3-9
}

Poster session

\section{Potential Cardioprotective Effect of L-citrulline against Isoproterenol Induced Myocardial Infarct: Focus on Antioxidants Activity}

\author{
Gregorius B Wikanendra ${ }^{1}$, Wawaimuli Arozal ${ }^{1}$, Andrea Laurentius ${ }^{1}$, Vetnizah Juniantito ${ }^{2}$, \\ Nafrialdi Agus ${ }^{1}$, Tzeto $\mathrm{H}$ Cong ${ }^{1}$
}

${ }^{I}$ Department of pharmacology, Faculty of medicine, Universitas Indonesia, Indonesia, ${ }^{2}$ Department of veterinary clinic, reproduction and pathology, Faculty of veterinary medicine, Bogor Agricultural University, Indonesia

Background : Cardiovascular diseases contribute more than 17 million deaths every year with coronary heart disease (CHD) being the greatest contributor. One of the medication that is being used to treat CHD was the organic nitrates but long term usage will cause resistance. L-arginine, a substrate for NO synthase (NOS), shows potential as supplementation to treat $\mathrm{CHD}$ for its vasodilative and antioxidative effects which protect the heart against myocardial infarction (MI) without causing resistance in long term. L-citrulline, precursor to L-arginine, serves as a better mean to supplement Larginine due to its greater oral bioavailability. The aim of this study is to find the potential cardioprotective effect of 1 citrulline against MI, with focus on antioxidants activity.

Method : This study used 24 male wistar rats weighed 190-220 grams which divided to 4 groups. 1st and 2nd group received water while $3 \mathrm{rd}$ and 4 th group received $300 \mathrm{mg} / \mathrm{kgBW}$ (low dose) and $600 \mathrm{mg} / \mathrm{kgBW}$ (high dose) of 1-citrulline daily respectively. Treatment were given perorally from day 1 to 6 . Induction of MI were done by injecting isoproterenol $85 \mathrm{mg} / \mathrm{kgBW}$ intraperitoneally on day 4 and 5 for group 2,3 and 4 while 1 st group served as sham. Blood pressure and ECG were recorded on day 3 and 6 . Subjects were sacrificed on day 6 to collect blood and tissue samples. Samples were processed to measure tissue damage by Haematoxylin-Eosin staining, lactate dehydrogenase (LDH) level and aspartate aminotransferase (AST) level and antioxidants activity by superoxide dismutase (SOD) and catalase activity and glutathione (GSH) level and malonidealdehyde (MDA) level.

Results : Isoproterenol injection caused myocardial damage and significantly lowered systolic and diastolic blood pressure, serum SOD activity and tissue GSH level and elevated tissue MDA level on all induced groups $(\mathrm{p}<0.05)$. Tissue catalase activity only significantly lowered in 2nd group $(\mathrm{p}<0.05)$ while serum AST level only significantly increased in low dose group ( $\mathrm{p}<0.05)$. There was no significant difference between groups for serum LDH level.

Conclusion : This study shows that isoproterenol injection successfully cause myocardial infarction in all induced subjects. 1-citrulline supplementation fails to provide cardioprotective effects through its antioxidants activity. 